\title{
Design of DFIG Converters to Overcome Grid Faults Using Improved Stator Flux Based Field Oriented Control and STATCOM Controller
}

\author{
D. V. N. Ananth ${ }^{1}$ - G. V. Nagesh Kumar ${ }^{2}$
}

Received: 30 April 2015 / Accepted: 5 September 2018 / Published online: 21 September 2018

(C) Springer Nature Singapore Pte Ltd. 2018

\begin{abstract}
The doublyfed induction generator based wind energy conversion system is attracting the energy production market for the last decade. It is due to the facts like large rating single unit, withstand to grid disturbances, independent real and reactive power flow control and mainly low power converter ratings. However, under severe short circuit faults, the doubly fed induction generator (DFIG) is constrained to be in synchronism with the grid as is posed by the modern grid codes. For this, dynamic and transient response of DFIG converter unit control needs to be modified for sustainability and reliability. The article will show that DFIG will follow better grid code requirements using proposed improved stator flux based field oriented control scheme in Rotor Side Converter. Further, a three levels STATCOM controller is externally placed near the grid point to further increase its capability under transients. This can be achieved by minimizing DC offset currents to zero by controlling stator flux decay during transients. The stator $\mathrm{d}$ and $\mathrm{q}$ axis flux wave is circular during steady state and also deviate its shape and characteristics during transients. This feature is restored using proposed FOC technique and helps in maintaining a minimum voltage and current in rotor and stator circuit. This technique not only improves LVRT but also ensures a longer lifetime of the machine during major disturbances.
\end{abstract}

Keywords DFIG $\cdot$ Field oriented control $\cdot$ LVRT $\cdot$ STATCOM

\section{Introduction}

Among different wind turbine based generators, the Doubly Fed Induction Generator is prominent due to its maximum power extraction capability, variable speed generator running operation, and strong reactive power control, sustaining operation under low voltage and high voltage faults, economically feasible back to back converters and independent and quicker real and reactive power flow control . The reactive power control ability and competence enhancement is obtained with help of rotor side control (RSC) with

\footnotetext{
D. V. N. Ananth

nagaananth@gmail.com

G. V. Nagesh Kumar

gundavarapu_kumar@yahoo.com
}

1 Department of EEE, RAGHU Institute of Technology, Visakhapatnam, India

2 Vignan's Institute of Information Technology, Visakhapatnam, India
25 to $35 \%$ rating converter letting $\pm 25 \%$ variation in the rotor speed [1, 2].

Based on severity of the fault, the high voltages and/ or currents will enter into the rotor windings and will damage the rotor side power electronic converters. Several FRT methods for DFIG wind turbine (WTs) have been proposed in the literature to enhance the transient stability [3, 4]. When a three phases to ground grid fault occurs, a DC offset part of flux is produced in the sensitive DFIG stator, tending the rotor windings to effectively pump surge current into the RSC [5]. This surge current will damage the rotor side converter and the dc link capacitor as their rating is low. Likewise, asymmetric faults induce negative sequence flux components results in high currents with real and reactive power and electromagnetic torque oscillations [6-8]. Hence controlling this over current, crowbar circuit [9] is generally used to avoid which disable DFIG and makes grid into more dangerous state. So, advanced vector control techniques etc., are used to improve fault current and voltages of stator and rotor and to damp power and electromagnetic torque oscillations. However above methods in RSC does not provide significant reduction in rotor over currents. 
The application of STATCOM for improved performance during transients for grid connected DFIG are given in [10-24]. All these methods are summarized briefly as: 1) initially, using some external resistors called crowbars are used on the DFIG rotor side during the grid fault; and 2) superior techniques that inject series voltage to sustain the pre-fault voltages across the DFIG stator terminals with the help of external voltage-source converter. In these schemes, the dynamic voltage restorer mitigate the DIG terminals voltage dip during the grid faults. These shunt voltage compensation schemes like STATCOM can offer the subsequent advantages: 1) smooth low voltage fault ride through (LVFRT); 2) promising dynamic and transient stability; 3) adaptable for all types of grid faults; and 4) maintaining electromechanical energy conversion for short perturbations. But, these advantages are met only with the expense of an additional transformer, filters and VSC. Although the FACTS devices offers great transient response under fault operation with extra six switches, it is difficult to achieve a common shunt compensation method for entire wind park having multiple WTs. Under such situations, each DFIG WT must be capable with a full rated converter and a quicker response based RSC. This configuration needs the stator winding to be modelled using such fast and accurate control scheme. Also, necessarily some special arrangements are made between the wind turbine and the grid to improve its life and to meet the demanded performance during the faults.

In general stator stationary two axis stator (alpha, beta) flux trajectory will be a circle for DFIG during steady state. When a disturbance occurs, the trajectory and shape differs and takes time to reach its pre-disturbance state after relieving from disturbance. As per flux decay theorem, compared to decay in voltage and current, stator flux decay may not be at that rate and leads to damage of the induction generator. During this time both rotor voltage and current waveform will be distorted with low magnitude and high frequency which has to be at slip frequency. Similarly stator voltage and current magnitude decreases to small value based on distance and severity of fault. The rotor speed increases from a steady state value to higher values, electromagnetic torque oscillations in DFIG goes to nearly zero value with large pulsations and heavy inrush current enters into rotor circuit and without isolation from fault using crowbars etc, the DFIG will gets damaged. Hence if flux decay will be controlled by improving its trajectory and shape during fault and regaining its shape very quickly after fault, above adversity is eliminated.

For ensured flux trajectory and circular shape with controlled magnitude of flux, improved stator flux based field oriented control scheme (ISFOC) technique was developed. Under disturbance conditions, DC offset currents will be developed and due to this an exponential decay in flux takes place and converts to elliptical for single line to ground fault and a smaller circular trajectory with large swings and changing centre to circle is observed. Hence this method helps in decreasing DC offset current (DCOC) by changing stator synchronous frequency to grid reference synchronous frequency which further helps in restoring its shape and magnitude and makes system healthy and faster in action during transients. The further enhancement in dip in stator and rotor voltage and current waveform and improving rotor speed, a three level STATCOM was used. A comparison of ISFOC based system without and with STATCOM was done and analysis without ISFOC was done as text for references $[21,22]$.

The above said impact on DFIG can be reduced using a fast acting inner current control loop for rotor side converter with fast acting control technique and also taking support from surge current limiters or FACTS devices. To have fast acting controller, sophisticated and robust techniques are necessary with fast acting inner control loop with subjective change in the rotor and stator speed reference to limit the surge current during and after the fault. The flux decomposition is also controlled with our proposed control scheme. Energy storage system like SMES, BESS and capacitor banks and FACTS devices like STATCOM, DVR and fault current limiters are extensively used to enhance further the performance of DFIG during faults. The requirement of these external energy storage devices is, the converters of DFIG are of very low (30\%) rated. The techniques like feed-forward transient current control with PI and PIR are used, where stator and rotor current maintained nearly constant during symmetrical or asymmetrical faults. The LVRT issue with internal model control (IMC) with two degrees of freedom can also enhance operation of DFIG during faults.

This paper presents LOW VOLTAGE RIDE THROUGH behaviour using a Improved Stator Flux based Field Oriented Control (ISFOC) to reduce over currents along with aid of three levels STATCOM connected through bidirectional IGBT- diode switches to the dc link. The paper suggests that the external devices like STATCOM with robust control strategy if coordinated with DFIG converters will improve voltage profile and fault ride through under any type of grid disturbances.

\section{Modelling of Grid Connected DFIG Based Wind Turbine System}

The simple layout of DFIG grid connected STATCOM system is shown in Fig. 1. In this pitch angle controller is used for wind turbine control for extracting maximum power and improve mechanical efficiency and also to limit its operation during lower and higher wind speeds. The rotor side converter of DFIG is operated at slip frequency and will 


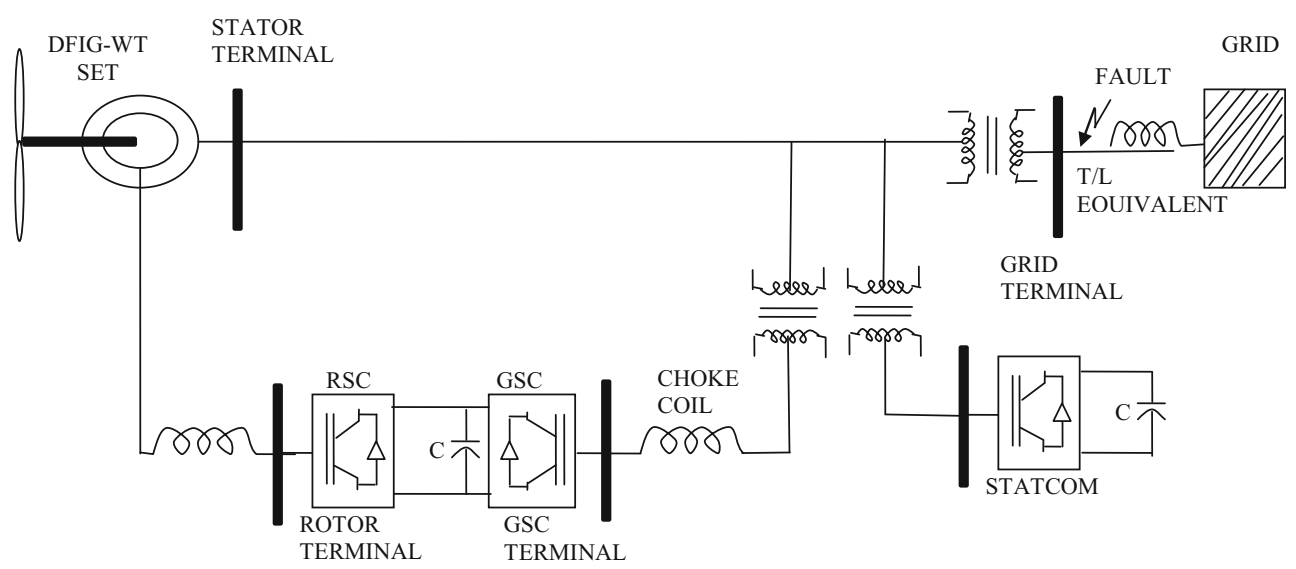

Fig. 1 Layout of DFIG, STATCOM based grid connected system

regulate the stator speed to maintain the grid frequency. This converter also helps extensively in extracting maximum power from the wind turbine, reactive power control and sustainability to grid disturbances. The overall efficiency and performance of DFIG can be enhanced y controlling the current flowing through it and the flux exchange between the stator and rotor flux. The grid side converter will maintain dc link voltage across the capacitor, reactive power supply to the grid and aids the rotor converter performance durig the faults. The STATCOM will compensate stator and rotor voltage and current of DFIG during transient conditions, leading to a safe operation of DFIG. This STATCOM will limit the fault surge current entering the rotor side converter and thereby increasing life time of the generator and also the stability of overall power system network. The modelling and design of wind turbine system and mathematical modeling of DFIG is described below.

Modelling of the Wind Turbine The kinetic energy in the wind makes the wind turbine to rotate with that much mechanical strength given by

$\mathrm{P}_{\text {mech }}=\frac{1}{2} \mathrm{Cp}(\lambda, \beta) \rho \pi \mathrm{r}^{2} v_{\omega}^{3}$

Here the mechanical wind turbine output power is $\mathrm{P}_{\text {mech }}$ Based on the wind speed $\left(v_{\omega}\right)$ and the coefficient of turbine power $\mathrm{C}_{\mathrm{p}}$, the turbine performance varies. This $\mathrm{Cp}$ is made to be optimal by controlling turbine blades tip speed ratio $(\lambda)$, and the pitch angle $(\beta)$ for a given radius of wind turbine blade (r) and specific density of air $(\rho)$ as [25].

$\operatorname{Cp}(\lambda, \beta)=0.5176\left(\frac{116}{\lambda_{\mathrm{i}}}-0.4 \beta-5\right) \mathrm{e}^{\frac{-21}{\lambda_{\mathrm{i}}}}+0.0068 \lambda$

The tip sped ratio depends on the radius of turbine blades, turbine rotating speed $\left(\omega_{\mathrm{t}}\right)$, and the wind speed. It can also be represented in terms of pitch angle as

$\lambda=\frac{\omega_{\mathrm{t}} \mathrm{r}}{v_{\omega}}$ and $\frac{1}{\lambda_{\mathrm{i}}}=\frac{1}{\lambda+0.08 \beta}-\frac{0.035}{\beta^{3}+1}$

and has to rotate at an optimal speed of $\left(v_{n}\right)$ described by

$v_{\mathrm{n}}=\sqrt[2]{\frac{2 \mathrm{P}_{\mathrm{sh}}}{\pi \rho \mathrm{r}^{3} \mathrm{C}_{\mathrm{p} \max }}}$

when the coefficient of power is maximum (Cp max) for a turbine shaft power $\left(\mathrm{P}_{\mathrm{sh}}\right)$. The maximum power output from a wind turbine at different optimal parameters is [25]

$\mathrm{P}_{\max }=\frac{1}{2 \lambda_{\mathrm{opt}}^{3}} \pi \rho \mathrm{C}_{\mathrm{p} \max } \mathrm{r}^{5} \omega_{\mathrm{opt}}^{3}$

Pitch Angle Controller The optimal power from the turbine can be achieved when the turbine blades sweep the maximum wind with certain kinetic energy. To maximum utilization of blades to cut the wind, blade angles are changed as this technique is known as pitch angle control as shown in Fig. 2 depending on wind speed direction and

Fig. 2 Pitch angle controller design

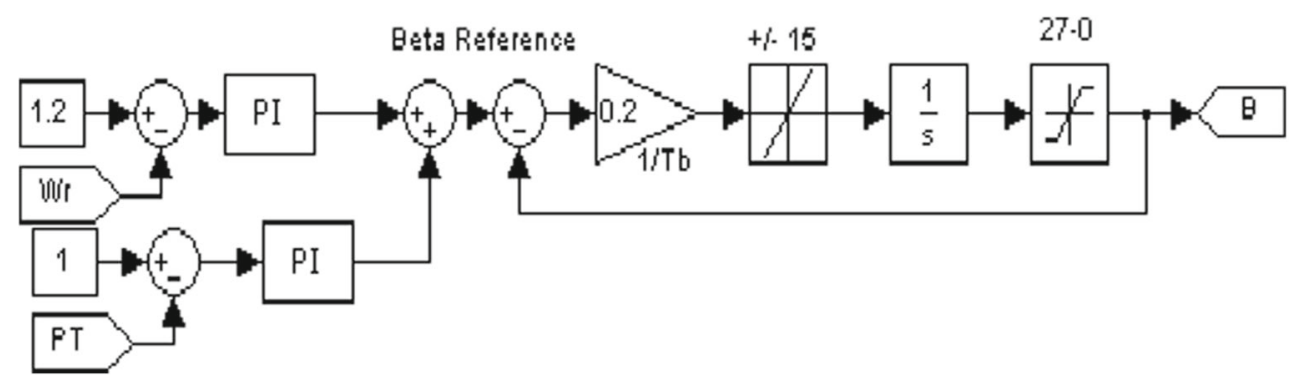


turbine mechanical power output. For simplicity in understanding, reference generator speed is taken as $\mathrm{W}_{\mathrm{r}}^{\mathrm{ref}}=1.2 \mathrm{pu}$ and actual generator speed $\mathrm{W}_{\mathrm{r}}$. The difference in reference and actual values is controlled and maintained to zero value using a tuned PI controller. Similarly, the difference in reference mechanical power $\left(\mathrm{P}^{*}=1\right)$ and actual turbine output power (PT) is controlled by another PI controller. The outputs from both PI controllers are added to get reference optimal pitch angle value $\left(\beta_{\text {ref }}\right)$. The closed loop pitch angle control is given in Fig. 2 [1].

Mathematically pitch angle control can be expressed as $\int \frac{1}{\mathrm{~T}_{\beta}}\left(\beta_{\mathrm{ref}}-\beta\right) d t$ At zero degrees, the wind direction is perpendicular to turbine blades and will sweep most of the wind, so maximum power is extracted from the turbine. This pitch angle varies in the range 0 to $27.5^{\circ} \%$ sased on wind speed, if is at $27 \%$, means either wind speed is very high known as cut-out wind speeds or is signalled when any external fault at grid may occurred.

\section{Mathematcal Modeling of DFIG Converters}

The role of rotor and grid side converters is described in the starting of the previous section. In this, the rotor voltage is expressed in terms of stator voltage and flux and in rotor current as these stator flux and rotor currents can be controllable when stator voltage changes abruptly during disturbances. How effectively these flux and current are controlled, that much promising the DFIG performance as per the requirement. In this section, the rotor terminal voltage in terms of back emf is first developed to describe the effect of stator flux and rotor current parameters when grid voltage disturbance takes place. Later, RSC and GSC control schemes mathematical modelling is described.

\section{Rotor Side Converter Control}

The equivalent circuit of DFIG is shown in Fig. 3 in an arbitrary reference speed of $\omega$ with a rotating reference frame [5] is considered in this paper. The equations in dq reference frame are:

The stator voltage Vs in terms of stator flux $\psi \mathrm{s}$ is represented as:

$$
\begin{aligned}
V_{s} & =\omega_{s} \psi_{s} \\
\mathrm{~V}_{0 \mathrm{r}}^{\mathrm{s}} & =\frac{\mathrm{L}_{\mathrm{m}}}{\mathrm{L}_{\mathrm{s}}}\left(\frac{\mathrm{d}}{\mathrm{dt}}-\mathrm{j} \omega_{\mathrm{s}}\right) \Phi_{\mathrm{s}}^{\mathrm{s}} \\
X_{r} & =\omega_{s} L_{r} ; X_{s}=\omega_{s} L_{s} ; s=\frac{\omega_{s l i p}}{\omega_{s}}
\end{aligned}
$$

In the Eq. 7, the rotor and stator reactance (Xr and $\mathrm{Xs}$ ) are defined in terms of synchronous angular speed $(\omega \mathrm{s})$, inductance (Ls) and slip angular frequency ( $\omega$ slip).

The stator $\mathrm{d}$ and $\mathrm{q}$ axis reactance are given in Eq. 2, gives relation in terms of $\mathrm{d}$ and q-axis flux and current components and also in terms of stator terminal voltage. Here Xm is mutual component of reactance of DFIG stator and rotor. From the basic mathematical model of DFIG, we know that

$$
\begin{aligned}
& V_{s}=R_{s} i_{s}+\rho \psi_{s} \\
& V_{r}=R_{r} i_{r}+\rho \psi_{r}-j \omega_{r} \psi_{r}
\end{aligned}
$$

The rotor voltage equation (8b) can be rewritten as

$$
V_{r}=R_{r} i_{r}+\left(\rho--j \omega_{r}\right) \psi_{r}
$$

In the Eq. 8b1, the rotor and stator reactance $\left(\mathrm{L}_{\mathrm{r}}\right.$ and $\left.\mathrm{L}_{\mathrm{s}}\right)$ are defined in terms of synchronous angular speed $\left(\omega_{\mathrm{s}}\right)$, inductance $\left(\mathrm{L}_{\mathrm{s}}\right)$ and slip angular frequency $\left(\omega_{\text {slip }}\right)$. Here $\mathrm{L}_{\mathrm{m}}$ is mutual inductance component of reactance of DFIG stator


Fig. 3 Equivalent circuit of DFIG 
and rotor. Here $\rho$ represents $\frac{\mathrm{d}}{\mathrm{dt}}$ The basic stator and rotor flux and current components are given in Eqs. 9a-9b1.

$\psi_{s}=L_{s} i_{s}+L_{m} i_{r}$

$i_{s}=\frac{\psi_{s}}{L_{s}}-\frac{L_{m}}{L_{s}} i_{r}$

$\psi_{r}=L_{r} i_{r}+L_{m} i_{s}$

$\psi_{r}=L_{r} i_{r}+\frac{L_{m}}{L_{s}}\left(\psi_{s}-L_{m} i_{r}\right)$

For DFIG, the stator and rotor inductances are equal to the sum of leakage inductance $\left(\mathrm{L}_{\mathrm{ls}}, \mathrm{L}_{\mathrm{lr}}\right)$ and mutual inductance (Lm) as

$L_{s}=L_{l s}+L_{m} ; L_{r}=L_{l r}+L_{m}$

The Eq. $8 \mathrm{~b} 1$ is rewritten replacing rotor flux with stator flux and rotor current parameters using Eq. 9b1, because, the rotor current is a known variable and can be controllable.

$V_{r}=R_{r} i_{r}+\left(\rho-j \omega_{r}\right)\left(L_{r} i_{r}+\frac{L_{m}}{L_{s}}\left(\psi_{s}-L_{m} i_{r}\right)\right)$

The Eq. 10 can be expanded and rewritten as in Eq. 11a. The aim of these derivations from Eqs. $11 \mathrm{a}-11 \mathrm{~d}$ is to find the rotor voltage in terms of rotor current and stator flux. The flux parameter variables will give the rotor instantaneous back emf at any given instant and helps in getting the DFIG performance under the transient.

$$
\begin{aligned}
V_{r}= & R_{r} i_{r}+\rho L_{r} i_{r}+\rho \frac{L_{m}}{L_{s}} \psi_{s}-\rho \frac{L_{m}^{2}}{L_{s}} i_{r}-j \omega_{r} L_{r} i_{r} \\
& -j \omega_{r} \frac{L_{m}}{L_{s}} \psi_{s}+j \omega_{r} \frac{L_{m}^{2}}{L_{s}} i_{r}
\end{aligned}
$$$$
V_{r}=i_{r}\left(R_{r}+\rho L_{r}-\rho \frac{L_{m}^{2}}{L_{s}}-j \omega_{r} L_{r}+j \omega_{r} \frac{L_{m}^{2}}{L_{s}}\right)
$$$$
+\left(\rho \frac{L_{m}}{L_{s}}-j \omega_{r} \frac{L_{m}}{L_{s}}\right) \psi_{s}
$$

$V_{r}=i_{r}\left(R_{r}+\rho\left(L_{r}-\frac{L_{m}^{2}}{L_{s}}\right)-j \omega_{r}\left(L_{r}-\frac{L_{m}^{2}}{L_{s}}\right)\right.$

$+\left(\rho-j \omega_{r}\right) \psi_{s} \frac{L_{m}}{L_{s}}$

$V_{r}=i_{r}\left(R_{r}+\left(\rho-j \omega_{r}\right) L_{r} \sigma\right)+\left(\rho-j \omega_{r}\right) \psi_{s} \frac{L_{m}}{L_{s}}$

where $\sigma=\left(L_{r}-\frac{L_{m}^{2}}{L_{s}}\right)$

Eliminating $\rho \Psi_{\mathrm{s}}$ and representing in terms of $\mathrm{V}_{\mathrm{s}}$ and $\mathrm{i}_{\mathrm{r}}$.

$$
\begin{aligned}
& \rho \psi_{s}=V_{s}-R_{s} i_{s} \\
& \rho \psi_{s}=V_{s}-\frac{R_{s}}{L_{s}}\left(\psi_{s}-L_{m} i_{r}\right)
\end{aligned}
$$

Using the Eq. 12b, the Eq. 11d can be rewritten as

$$
\begin{aligned}
V_{r}= & i_{r}\left(R_{r}+\left(\rho-j \omega_{r}\right) L_{r} \sigma\right. \\
& +\frac{L_{m}}{L_{s}}\left(V_{s}-\frac{R_{s}}{L_{s}} \psi_{s}+R_{s} \frac{L_{m}}{L_{s}} i_{r}\right)-j \frac{L_{m}}{L_{s}} \omega_{r} \psi_{s} \\
V_{r}= & i_{r}\left(R_{r}+\left(\frac{L_{m}}{L_{s}}\right)^{2} R_{s}+\left(\rho-j \omega_{r}\right) L_{r} \sigma\right. \\
& +\frac{L_{m}}{L_{s}}\left(V_{s}-\frac{R_{s}}{L_{s}} \psi_{s}-j \frac{L_{m}}{L_{s}} \omega_{r} \psi_{s}\right) \\
V_{r}= & \frac{L_{m}}{L_{s}}\left(V_{s}-\psi_{s}\left(\frac{R_{s}}{L_{s}}+j \omega_{r}\right)\right) \\
& +i_{r}\left(R_{r}+\left(\frac{L_{m}}{L_{s}}\right)^{2} R_{s}+\left(\rho-j \omega_{r}\right) L_{r} \sigma\right.
\end{aligned}
$$

The final equation for rotor voltage helps in examining the DFIG behaviour during steady state and under transient conditions. The first parameter in the right side gives the back emf of DFIG in terms of stator voltage and flux.

$V_{r}=V_{r o}+V_{k}$

where $V_{r o}=\frac{L_{m}}{L_{s}}\left(V_{s}-\psi_{s}\left(\frac{R_{s}}{L_{s}}+j \omega_{r}\right)\right)$ and $V_{k}=i_{r}\left(R_{r}+\right.$ $\left(\frac{L_{m}}{L_{s}}\right)^{2} R_{s}+\left(\rho-j \omega_{r}\right) L_{r} \sigma$

When this back emf ( $\left.\mathrm{V}_{\text {ro }}\right)$ flux is controlled effectively, the rotor side surge inrush current can be minimised effectively. This control in flux leads to the theory of proposed Improved Stator Flux based Field Oriented Control (IsFOC) scheme.

The basic stator and rotor flux components in terms of stator and rotor currents as given in Eqs. 15a-15d.

$\psi_{d s}=L_{s} i_{d s}+L_{m} i_{d r}$
$\psi_{q s}=L_{s} i_{q s}+L_{m} i_{q r}$
$\psi_{d r}=L_{r} i_{d r}-L_{m} i_{d s}$
$\psi_{q r}=L_{r} i_{q r}-L_{m} i_{q s}$

$\left\{\begin{array}{l}P_{s}=\frac{3}{2} V_{s} I_{q s}=-\frac{3}{2} \frac{X_{m}}{X_{s}} V_{s} I_{q r} \\ Q_{s}=\frac{3}{2} V_{s} i_{d s}=\frac{3}{2} V_{s}\left(\frac{V_{s}}{X_{s}}-\frac{X_{m}}{X_{s}} i_{d r}\right)=\left(\frac{3 V_{s}^{2}}{2 X_{s}}-\frac{3 X_{m} V_{s}}{2 X_{s}} i_{d r}\right) \\ S_{r}=P_{r}+j Q_{r}=\frac{3}{2} V_{r} I_{r}^{*}=\frac{3}{2}\left[\operatorname{real}\left(V_{r} I_{r}^{*}\right)+j \operatorname{Imag}\left(V_{r} I_{r}^{*}\right)\right. \\ P_{r}=\frac{3}{2}\left(V_{d r} I_{d r}+V_{q r} I_{q r}\right) \\ Q_{r}=\frac{3}{2}\left(V_{q r} I_{d r}-V_{d r} I_{q r}\right)\end{array}\right\}$

The DFIG apparent $(\mathrm{S})$, real $(\mathrm{P})$ and reactive $(\mathrm{Q})$ power flows from the stator and rotor (suffix $s$ or $r$ ) is described by Eq. 16. The control of rotor power is crucial to extract optimal power in steady state and flux demagnetising under transient states and can be achievd by rotor side converter (RSC). This rotor real and reactive power expressed in terms 
of stator power helps in understanding and controlling the DFIG performance in any state of operation. Described by

$P_{r}=\frac{3}{2}\left(V_{d r} \frac{2}{3} \frac{X_{s}}{X_{m}} \frac{Q_{s}}{V_{m}}+\frac{V_{d r} V_{s}}{X_{m}}+\frac{2 V_{q r} X_{s}}{3 X_{m} V_{s}} P_{s}\right)$

Rearranging the above rotor real power equation, we get,

$P_{r}=\frac{X_{s}}{X_{m}} \frac{V_{d r}}{V_{m}} Q_{s}+\frac{3}{2} \frac{V_{d r} V_{s}}{X_{m}}+\frac{X_{s} V_{q r}}{X_{m} V_{s}} P_{s}$

$Q_{r}=\frac{X_{s}}{X_{m}} \frac{V_{q r}}{V_{s}} Q_{s}+\frac{3}{2} \frac{V_{q r} V_{s}}{X_{m}}-\frac{X_{s} V_{d r}}{X_{m} V_{s}} P_{s}$

From the two Eqs. 17b and 17c, the rotor powers Pr and Qr can be controlled to adjust the stator powers injected to the grid. That is stator real power flow is independent of stator reactive power flows as shown in Eq. 16 which are last two equations. These powers depend on rotor voltages and stator voltage for a given machine.

\section{Grid Side Converter Control}

The GSC control circuit block diagram is shown in Fig. 4. During normal conditions, the reactive power will be zero or very low and hence stator power pumped to the grid will be high. This power control can do use the outer control loop of GSC. The reference power is obtained from the characteristic lookup table based on the DFIG adopted. This reference power is compared to actual power and is maintained using the PI control of GSC. This total mechanism is fast and can work for symmetrical as well as asymmetrical faults. Based on the wind speed measurement, using lookup table scheme, optimal reference mechanical power is estimated. This power has to be equal to the real power and so to maintain this, a simple tuned PI controller is used. The output of this PI controller is reference current to be maintained. The square of dc voltage control $\sqrt{V_{d c}^{2}-V_{d c}}$ is maintained using another PI controller to get required current to make the dc voltage across the capacitor almost constant. The two currents are compared with actual d-axis current and is controlled and maintained to the desired value by another PI controller. The output is the actual d-axis voltage and when manipulated with the decoupling and disturbance parameters, we will get reference GSC based d-axis voltage.

The $\mathrm{d}$ and $\mathrm{q}$ axis stator voltages are expressed as [5],

$\mathrm{V}_{\mathrm{ds}}=\mathrm{i}_{\mathrm{ds}} \mathrm{R}_{\mathrm{s}}-\omega_{\mathrm{s}} \Phi_{\mathrm{qs}}+\frac{\mathrm{d} \Phi_{\mathrm{ds}}}{\mathrm{dt}}$

$\mathrm{V}_{\mathrm{qs}}=\mathrm{i}_{\mathrm{qs}} \mathrm{R}_{\mathrm{s}}-\omega_{\mathrm{s}} \Phi_{\mathrm{ds}}+\frac{\mathrm{d} \Phi_{\mathrm{qs}}}{\mathrm{dt}}$

The grid side converter voltage is given by

$\mathrm{V}_{\mathrm{dg}}=\left(\mathrm{i}_{\mathrm{dg}}^{*}-\mathrm{i}_{\mathrm{dg}}\right) \mathrm{R}_{\mathrm{s}}-\omega_{\mathrm{s}} \mathrm{L}_{\mathrm{g}} \mathrm{i}_{\mathrm{qg}}+\mathrm{V}_{\mathrm{ds}}$

$\mathrm{V}_{\mathrm{qg}}=\left(\mathrm{i}_{\mathrm{qg}}^{*}-\mathrm{i}_{\mathrm{qg}}\right) \mathrm{R}_{\mathrm{s}}-\omega_{\mathrm{s}} \mathrm{L}_{\mathrm{g}} \mathrm{i}_{\mathrm{dg}}$

The stator d and q axis flux $\Phi_{\mathrm{qs}}$ and $\Phi_{\mathrm{qs}}$ and the suffix 's' represents stator, where ' $\mathrm{g}$ ' is for grid. The direct and

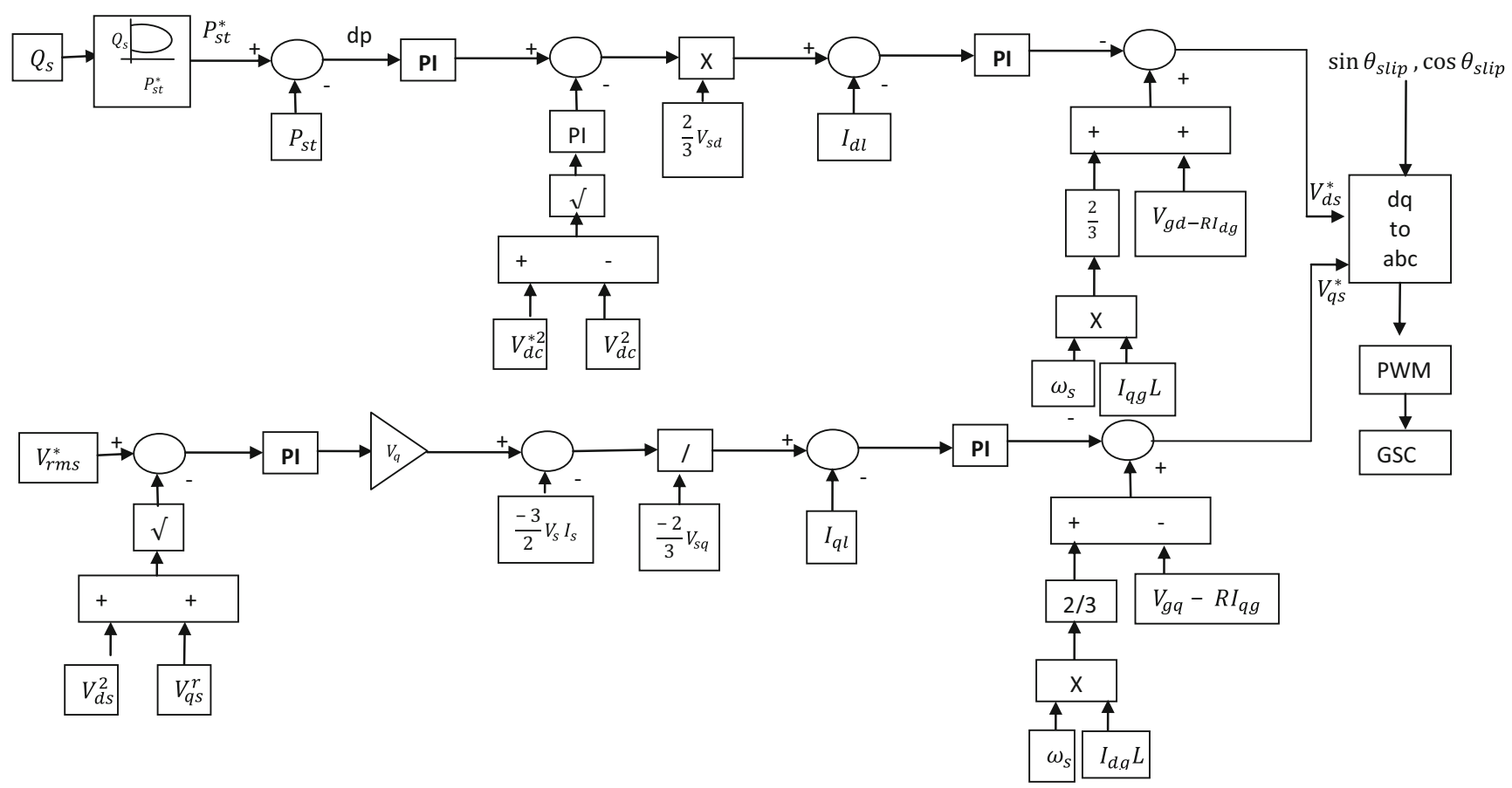

Fig. 4 Design of GSC controller for DFIG 
quadrature axis grid current $i_{d g}$ and $i_{\text {qg }}$ flows depend on dc capacitor voltage to get reference $i_{d g}^{*}$ and $i_{q g}^{*}$ [8]. The cross couple grid terms $-\omega_{\mathrm{s}} \mathrm{L}_{\mathrm{g}} \mathrm{i}_{\mathrm{qg}}, \mathrm{V}_{\mathrm{ds}}$ and $\omega_{\mathrm{s}} \mathrm{L}_{\mathrm{g}} \mathrm{i}_{\mathrm{dg}}$, which are added to the output of PI current controller to circumvent coupling effects to produce reference two axis voltages. These two axis voltages are transformed into three axis and is given to pulse width modulation to give pulses to grid side converter.

\section{Sub-blocks Desin of Rotor Side Converter Control}

Also, from basic equations of DFIG [8],

$\mathrm{V}_{\mathrm{dr}}=\left(\mathrm{R}_{\mathrm{r}}+\frac{\mathrm{dL_{ \textrm {r } } ^ { \prime }}}{\mathrm{dt}}\right) \mathrm{i}_{\mathrm{dr}}-\mathrm{s} \omega_{\mathrm{s}} \mathrm{L}_{\mathrm{r}}^{\prime} i_{\mathrm{qr}}+\frac{\mathrm{L}_{\mathrm{m}}}{\mathrm{L}_{\mathrm{s}}} \mathrm{V}_{\mathrm{ds}}$

$\mathrm{V}_{\mathrm{qr}}=\left(\mathrm{R}_{\mathrm{r}}+\frac{\mathrm{dL}_{\mathrm{r}}^{\prime}}{\mathrm{dt}}\right) \mathrm{i}_{\mathrm{qr}}-\mathrm{s} \omega_{\mathrm{s}} \mathrm{L}_{\mathrm{r}}^{\prime} \mathrm{i}_{\mathrm{dr}}+\frac{\mathrm{L}_{\mathrm{m}}}{\mathrm{L}_{\mathrm{s}}}\left(\mathrm{V}_{\mathrm{qs}}-\omega \Phi_{\mathrm{ds}}\right)$

Where $\omega$ is rotor speed, $\omega_{\Phi s}$ is speed of stator flux, $\omega_{\mathrm{S}}$ is synchronous speed. The control circuit of RSC for low voltage ride through issues is described in Fig. 5(i) with proposed ISFOC. The right side corner with subsystem 2 is a sub-circuit of the controller for ISFOC technique and its design is shown in Fig. 9.

The Eqs. 20a and 20b equationx are rewritten in terms of decoupled parameters and are designed for RSC controller as in Eqs. 21a and 21b.

$\sigma \mathrm{V}_{\mathrm{dr}}=\sigma \mathrm{L}_{\mathrm{r}} \frac{\mathrm{dI}_{\mathrm{dr}}}{\mathrm{dt}}-\omega_{\mathrm{s}} \Phi_{\mathrm{qr}}+\frac{\mathrm{L}_{\mathrm{m}}}{\mathrm{L}_{\mathrm{s}}}\left(\mathrm{V}_{\mathrm{ds}}-\mathrm{R}_{\mathrm{s}} \mathrm{I}_{\mathrm{ds}}+\omega_{1} \Phi_{\mathrm{qs}}\right)$

$\sigma \mathrm{V}_{\mathrm{qr}}=\sigma \mathrm{L}_{\mathrm{r}} \frac{\mathrm{dI}_{\mathrm{qr}}}{\mathrm{dt}}-\omega_{\mathrm{s}} \Phi_{\mathrm{dr}}-\frac{\mathrm{L}_{\mathrm{m}}}{\mathrm{L}_{\mathrm{s}}}\left(\mathrm{R}_{\mathrm{s}} \mathrm{I}_{\mathrm{qs}}+\omega_{1} \Phi_{\mathrm{ds}}\right)$

This synchronous speed has to be changed from $\omega_{\mathrm{s}}$ to a new synchronous speed value as described in flowchart in Fig. 10 $\omega_{\mathrm{s}}^{\prime}$ as is represented here as $\omega_{1}$.

The simplified RSC block diagram is shown in Fig. 5 (ii). The rotor speed is multiplied with pole numbers and is subtracted from angular grid synchronous frequency. Later integrated and given a $90^{\circ}$ phase shift to get rotor slip injection frequency angles $\left(\theta_{\mathrm{S}}\right)$. At this slip frequency RSC converter injects current into the rotor circuit to control the rotor speed for optimum value and to control grid reactive power. The stator voltage magnitude is compared and controlled using PI controller to get q-axis current.

Similarly rotor actual speed and optimal speed reference are controlled using PI controller to get d-axis reference current. They are compared with an actual rotor $\mathrm{d}$ and $\mathrm{q}$ axis currents and controlled with tuned PI controllers to get the rotor injecting $d$ and $q$ axis voltages. The $d$ and $q$ voltages are converted into three axis abc voltage by using phase locked loop (PLL) with inverse parks transformation and is given to a PWM pulse generator for getting pulses to RSC converter.

The d-axis decoupled voltage derivation block diagram is shown in Fig. 5 (iii). The $\mathrm{d}$ and $\mathrm{q}$ axis stator flux and stator flux magnitude derivation block diagram is shown in Fig. 5 (iv). The flux derivation technique helps in understanding the operation of DFIG during steady state and transient state.

\section{Mathematcal Analysis of RSC and GSC Converters for Grid Connected DFIG During Transient State}

\section{Three Phase Symmetrical Faults}

The stator voltage will reach zero magnitude during severe three phase's symmetrical fault of very low impedance and stator flux $\Phi_{\mathrm{s}}$ gets reduced to zero magnitude. The decay in flux is not as rapid as in voltage and delay is due to inertial time lag $\tau_{\mathrm{s}}=\frac{\mathrm{L}_{\mathrm{s}}}{\mathrm{R}_{\mathrm{s}}}$ effecting the rotor induced Electromotive Force $(\mathrm{EMF}) \mathrm{V}_{\mathrm{Or}}$. The flux during fault is given by

$\Phi_{\mathrm{sf}}^{\mathrm{s}}=\Phi_{\mathrm{s}}^{\mathrm{s}} \mathrm{e}^{-\mathrm{t} / \tau_{\mathrm{s}}}$

and $\frac{\mathrm{d} \Phi_{\mathrm{sf}}^{\mathrm{s}}}{\mathrm{dt}}$ is negative, indicating its decay. Using Eq. 22 in Eq. 6 b

$\mathrm{V}_{0 \mathrm{r}}^{\mathrm{s}}=-\frac{\mathrm{L}_{\mathrm{m}}}{\mathrm{L}_{\mathrm{s}}}\left(\frac{1}{\tau_{\mathrm{s}}}+\mathrm{j} \omega\right) \Phi_{\mathrm{s}}^{\mathrm{s}} \mathrm{e}^{-\mathrm{t} / \tau_{\mathrm{s}}}$

Converting the above equation in the rotor reference frame and by neglecting $\frac{1}{\tau_{\mathrm{s}}}$

$\mathrm{V}_{0 \mathrm{r}}^{\mathrm{s}}=-\frac{\mathrm{L}_{\mathrm{m}}}{\mathrm{L}_{\mathrm{s}}}(\mathrm{j} \omega) \Phi_{\mathrm{s}}^{\mathrm{s}} \mathrm{e}^{-\mathrm{j} \omega \mathrm{t}}$

By substituting $\Phi_{\mathrm{s}}^{\mathrm{s}}=\frac{\mathrm{V}_{\mathrm{s}}^{\mathrm{s}}}{\mathrm{j} \omega_{\mathrm{s}}} \mathrm{e}^{-\mathrm{j} \omega_{\mathrm{s}} \mathrm{t}}$ in Eq. 23b

$\mathrm{V}_{0 \mathrm{r}}^{\mathrm{r}}=-\frac{\mathrm{L}_{\mathrm{m}}}{\mathrm{L}_{\mathrm{s}}}(1-\mathrm{s}) \mathrm{V}_{\mathrm{s}}$

$\left|\mathrm{V}_{0 \mathrm{r}}^{\mathrm{r}}\right|$ is proportional to (1-s).

Converting Eq. $6 \mathrm{~b}$ into rotor reference frame

$\mathrm{V}_{\mathrm{r}}^{\mathrm{r}}=\mathrm{V}_{0 \mathrm{r}}^{\mathrm{r}} \mathrm{e}^{-\mathrm{j} \omega \mathrm{t}}+\mathrm{R}_{\mathrm{r}} \mathrm{i}_{\mathrm{r}}^{\mathrm{r}}+\sigma \mathrm{L}_{\mathrm{r}} \frac{\mathrm{di}_{\mathrm{r}}^{\mathrm{r}}}{\mathrm{dt}}$

Thus rotor equivalent circuit derived from Eq. 24 is as shown in Fig. 6 [11].

A considerable decrease in pre-fault steady state voltage $\mathrm{V}_{0 \mathrm{r}}^{\mathrm{r}}$ to certain fault voltage during a three phase fault was explained in above analytics. However, RSC converter is designed to meet $\mathrm{V}_{\mathrm{r}}^{\mathrm{r}}$ to match $\mathrm{V}_{0 \mathrm{r}}^{\mathrm{r}}$ for rotor current control and the design has to be made for rating of only $35 \%$ of stator rated voltage. The voltage dip during fault is adopted independently or in coordination by using two techniques.

During fault, at first instant, $\Phi_{\mathrm{s}}$ does not fall instantly (21a) as shown in the flux and voltage trajectories in Fig. 6. If the machine is running at super synchronous speed with slip (s) near to $-0.2 \mathrm{pu}$, during fault, rotor speed further increases based on the term (1-s) as given by Eq. 21a. The 
above speed change is uncontrollable for a generator having higher electrical and mechanical inertia constants. In order to control the rotor current change, $\mathrm{V}_{\mathrm{r}}^{\mathrm{r}}$ has to be increased.
Based on the first reason listed above, a voltage $V_{\Phi s}$ has to be injected in the feed forward path for improving the rotor dip to reach to its near steady state value. Converting



(i): RSC controller with ISFOC technique

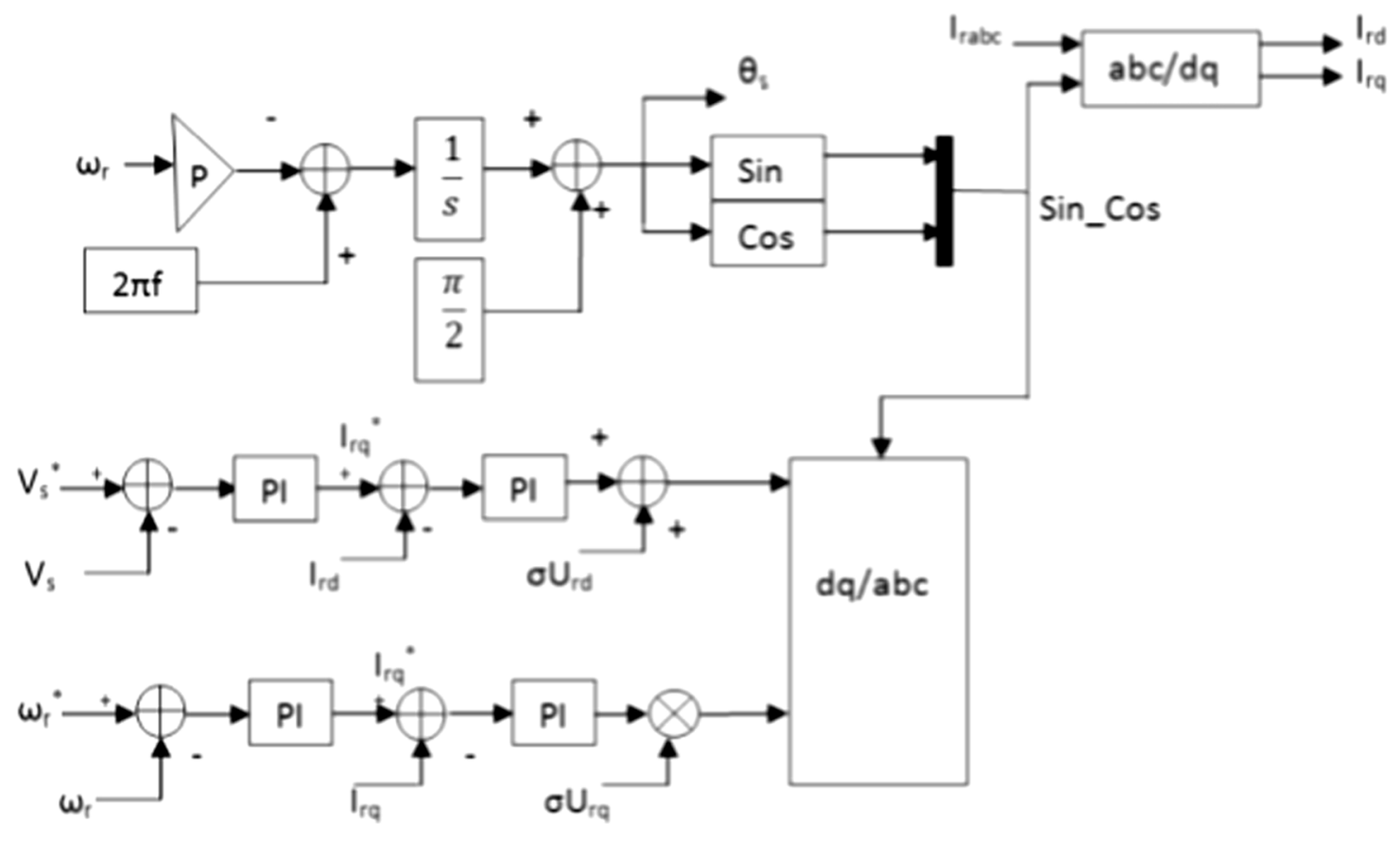

(ii) simplified RSC controller design

Fig. 5 Enhanced FOC control technique with the PI controller adopted for RSC 


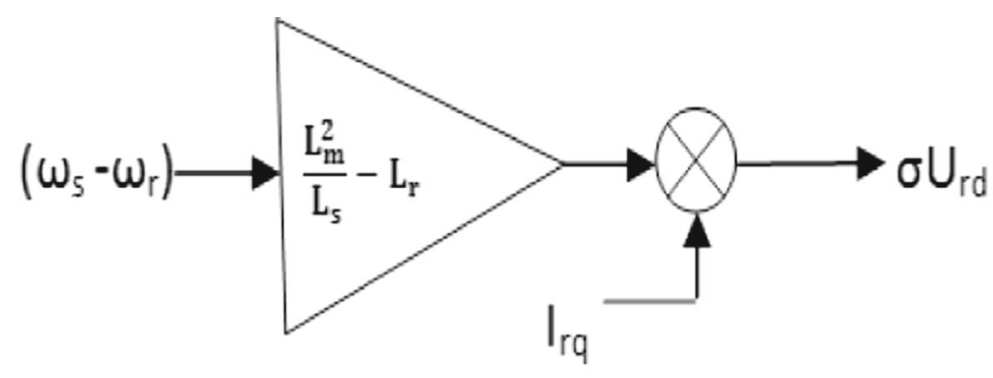

(iii) decoupled rotor voltage d-axis parameter



(iv) stator flux estimation block diagram

Fig. 5 (continued)

the Eq. 23 b into a synchronous reference frame and by considering direct alignment of $\Phi_{\mathrm{ds}}$ with $\Phi_{\mathrm{s}}$ we get,

$\mathrm{V}_{\Phi \mathrm{s}}=-\frac{\mathrm{L}_{\mathrm{m}}}{\mathrm{L}_{\mathrm{s}}} \omega \Phi_{\mathrm{ds}}$

The second reason listed above is compensated by replacing $\mathrm{s} \omega_{\mathrm{s}}$ with $\left(\omega_{\mathrm{s} \Phi}-\omega\right)$ in cross coupling terms $s \omega_{s} L_{r}^{\prime} i_{\mathrm{qr}}$ and $s \omega_{s} L_{r}^{\prime} i_{\mathrm{dr}}$. The reduction in magnitude and frequency of



Fig. 6 The rotor equivalent circuit flux $\Phi_{s}$, and alignment of flux with the stator voltage without rate of change in flux angle $\theta_{\Phi s}$ indicate dc offset component in flux. It is better observed in the voltage and flux trajectories shown in Fig. 7 for TLG and Fig. 8 during DLG fault.

$\frac{d \theta_{\varphi s}}{d t}=\omega_{\varphi s}=0=\omega_{f}$

where, $\omega_{f}$ is the speed of stator flux during fault.

The voltage injection components $(21 \mathrm{a}, 21 \mathrm{~b})$ and compensating components discussed above are estimated with enhanced flux oriented scheme with internal speed estimator based on DCOC and flux trajectory is shown in Fig. 9 whose flowchart is shown in Fig. 10 and the determined values are incorporated in RSC controller shown in Fig. 5.

\section{Asymmetric Faults}

The same control technique is employed for single phase to ground as well as two phase to ground faults. But due to presence of positive and negative sequence components, the 




Fig. 7 Voltage and flux trajectories for symmetric (TLG) fault

rate of change in flux angle $\theta_{\varphi s}$ and magnitude change in flux is observed [4], given by

$$
\frac{d \theta_{\varphi s}}{d t}=\omega_{\varphi s}=\frac{\left(V_{\beta s} \varphi_{\alpha s}-V_{\alpha s} \varphi_{\beta s}\right)}{\left(\varphi_{\alpha s}^{2}+\varphi_{\beta s}^{2}\right)}=\omega_{f}
$$

\section{Design of STATCOM and Improved Stator Flux Based FOC (IsFOC) Controller for LVRT Issue for DFIG}

The STATCOM controller is used for compensation of voltage at PCC and Improved Stator Flux based Field



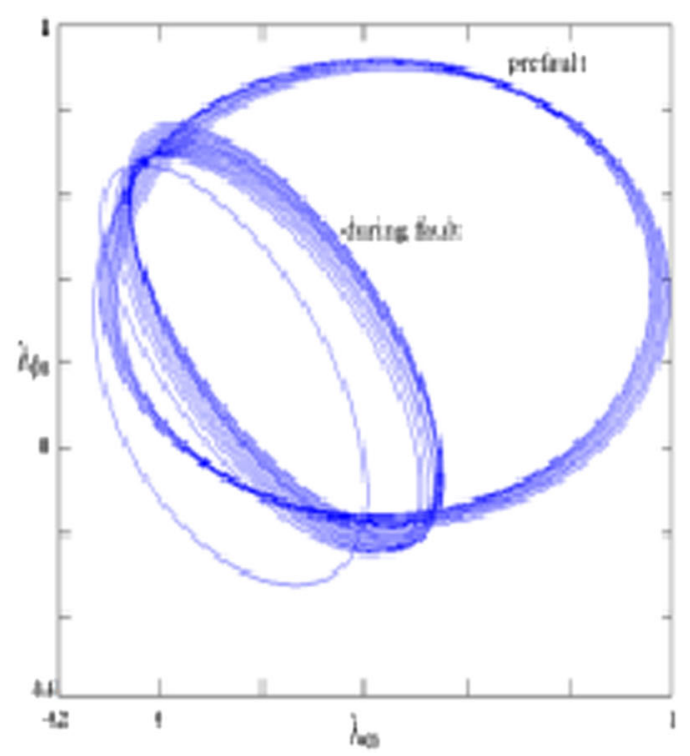

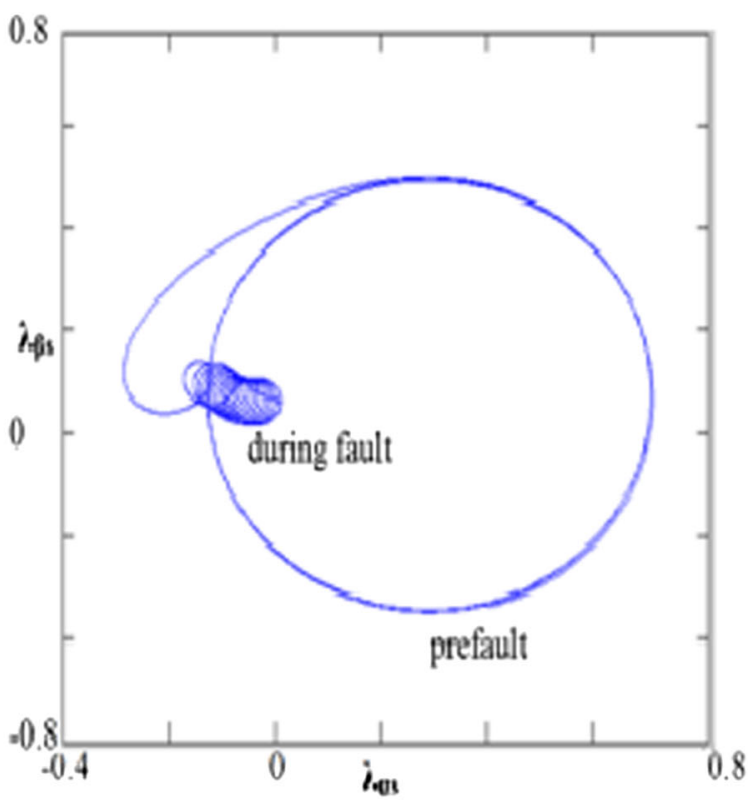

Oriented Control technique (IsFOC) is used for compensation of stator and rotor current of DFIG beyond the point of STATCOM controller. Compared to conventional FOC, flux decay rate is controlled by using this technique by controlling the DC offset current (DCOC) which is sub-transient DC component current of the generator. This controller technique further helps in maintaining the flux trajectory path of stator components not to go farther distance from centre of radius and reaching its pre-fault state even when the fault is not yet cleared. The techniques for STATCOM and ISFOC are described below.

Fig. 8 Voltage and flux trajectories for single phase to ground fault 


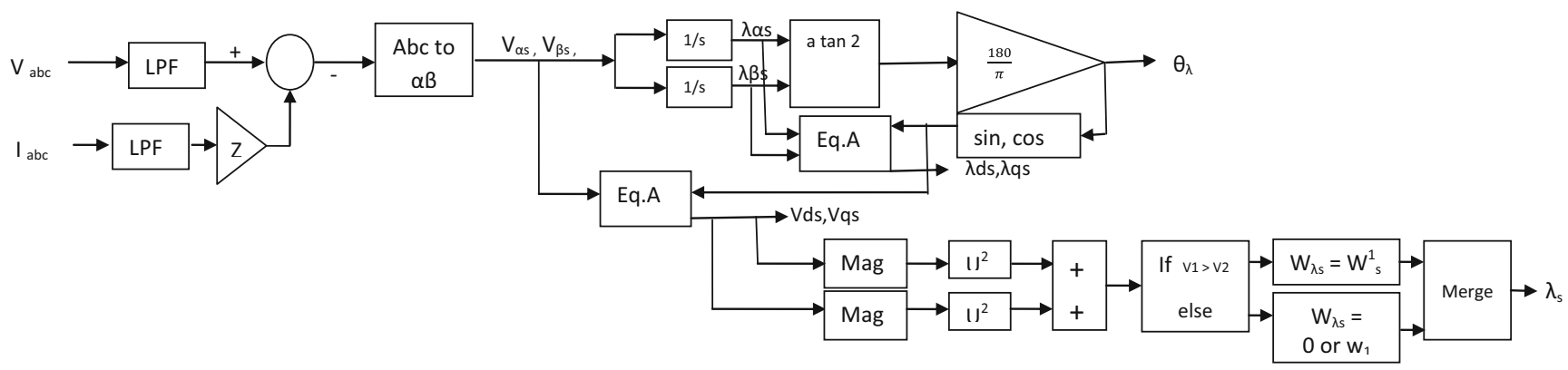

Fig. 9 ISFOC control loop design with DCOC and rotor flux trajectory control

\section{Voltage Mitigation by STATCOM}

The current injection and voltage to be compensated at PCC for safe operation and compensation are derived in this section with references from [20-23] and modified as per our work. The quadrature and direct axis voltages of STATCOM are given by

$$
\begin{aligned}
V_{q s t} & =M V_{d c_{s t}} \cos \left(\theta_{s t}\right) \\
V_{d s t} & =M V_{d c_{s t}} \sin \left(\theta_{s t}\right)
\end{aligned}
$$

Where $\mathrm{M}$ is the modulation index of PWM $\theta_{\mathrm{st}}$ is the load angle of STATCOM which is equal to $\theta_{\mathrm{PCC}}+\alpha$, with $\theta_{\mathrm{PCC}}$



Fig. 10 Scheme of enhanced flux oriented control where, DCOC = DC offset component of flux, $R \Phi s=$ radius of flux trajectory and $\alpha$ are load angle at PCC and STATCOM power angle in degrees. $\mathrm{V}_{\mathrm{dc}_{\mathrm{st}}}$ is the STATCOM DC voltage across the capacitor.

From literature compared to two levels STATCOM, three level STATCOM will work much better with good voltage and power factor compensation value, hence three level STATCOM was considered. The dip in the PCC voltage due to asymmetrical or symmetrical fault is compensated by STATCOM and the difference current compensation is given by

$\frac{d V_{d c_{s t}}}{d t} C_{s t}=2 \pi f\left[I_{d c_{s t}}-\frac{V_{d c_{s t}}}{R_{s t}}\right]$

Where $\mathrm{C}_{\mathrm{st}}$ is STATCOM voltage source converter (VSC) capacitor, $I_{d c_{s t}}$ STATCOM injecting current and $R_{s t}$ is the voltage drop across switches, transformer and inductive filters between STATCOM and PCC terminals.

The current injected by three level STATCOM is given by

$I_{d c_{s t}}=M I_{q_{s t}} \cos \left(\theta_{s t}\right)+M I_{d_{s t}} \sin \left(\theta_{s t}\right)$

\section{ISFOC Control Technique}

The ISFOC method of improving field flux oriented control technique helps in improving the performance of RSC controller of DFIG under fault conditions is described in Fig. 5. The DCOC observer does two actions

a) the change in flux values of stationary frame stator references $\left(\Phi_{\alpha s}, \Phi_{\beta s}\right)$ for tracking radius of trajectory and

b) DCOC for offset change in stationary fluxes $\left(\Phi_{d c \alpha s}\right.$, $\left.\Phi_{d c \beta s}\right)$ during fault conditions and controlling them

The first action in the design objective helps in maintaining the circular trajectory point and to attain its prefault state having same circle radius and centre. This will improve the rate of change in flux decay accordingly which will improve the transient response described by Eq. 14. The second action deals with effective control and maintenance of dc offset current component almost zero in magnitude using DCOC technique.

Hence from these two actions during grid disturbances, if former one is greater, it will change the flux and voltage 
trajectory by changing the stator synchronous frequency flux speed $\left(\omega_{\Phi s}\right)$ changes to synchronous grid frequency flux $\left(\omega_{s}\right)$. Otherwise $\omega_{\Phi s}$ changes to fault angular frequency value and is injected to RSC voltage control loop as error compensator.

\section{Result Analysis}

The MATLAB/SIMULINK based DFIG system for LOW VOLTAGE RIDE THROUGH issue enhancement with ISFOC technique and three levels STATCOM controller are described below under two cases with double phase and three phases to ground fault with fault resistance $0.001 \Omega$ at PCC during 0.8 to $1 \mathrm{~s}$ and the parameters of the test system are shown in the Appendix before the references.

Case a: Double Line to Ground (DLG) Fault Without and with STATCOM This type of fault mostly but severity on system disturbance is low. From Fig. 12a, b, it is observed that rotor voltage disturbance is low without or with STATCOM but rotor current increases from 0.2 pu to nearly $0.48 \mathrm{pu}$ (per-unit) without STATCOM and $0.2 \mathrm{pu}$ to $0.3 \mathrm{pu}$ with STATCOM. Hence fault current entering to rotor is minimized using STATCOM. Compared to results from [21] or [22], with conventional FOC, ISFOC will improve current and voltage drooping values during fault.

During DLG fault, stator of DFIG mostly gets affected due to severe fault inrush current entering into it. This makes stator voltage and current in general decreases drastically, but flux decay takes time which induces DC offset current in stator which damages stator and rotor windings if current further reaches rotor of DFIG. Hence this offset DC current is reduced by ISFOC flux controller scheme explained in previous section. The rotor, stator and grid voltage drooping during DLG are shown in Fig. 11a is without STATCOM and Fig. $11 \mathrm{~b}$ with STATCOM. The voltage across STATCOM is shown in the bottom graph of Fig. 11b. Similarly for DLG fault, the stator, rotor, grid and STATCOM current without and with STATCOM is in Fig. 12a and b. It is observed that during DLG fault, the line with fault gets voltage decreased while other two healthy phases voltage increases from its nominal volues and further increase beyond particular value is controlled using STACTOM action. The rms voltage and current fluctuations during the fault are comparatively reduced using the proposed STATCOM controller and due to its current compensation are shown in Fig. 11c, d for voltage, Fig. 12c and d for current.

The dc link capacitor voltage, rotor speed and electromagnetic torque without and with STATCOM is in Fig. 13a and $b$. It is observed that DC capacitor voltage ripples increases without STATCOM than with STATCOM, therefor RSC and GSC voltage changes much. With ISFOC technique dc voltage at capacitor is maintained nearly constant, otherwise during fault, this dc voltage decreases during fault and increases like impulse voltage just after relieving of fault. Hence ISFOC is much better technique than conventional FOC.

From the STATCOM voltage and current waveforms, during transient state, STATCOM current increases and that respective voltage changes in healthy and faulty lines are compensated. The spikes in the voltages during steady state helps in power factor control during steady state and these spikes are controlled by using inductor in series with the STATCOM phases which are generally used for PQ issues system. In our system, inductor was not used. The

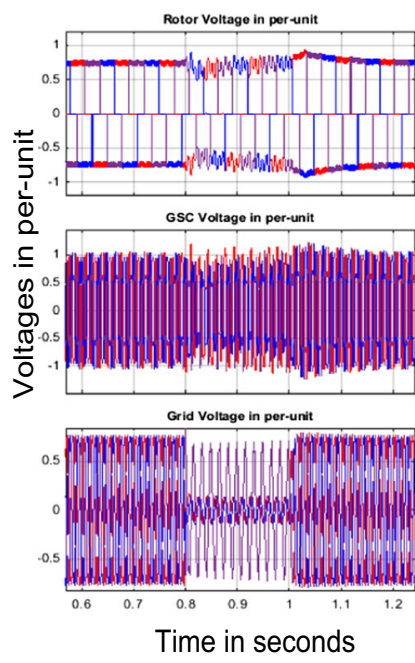

(a)

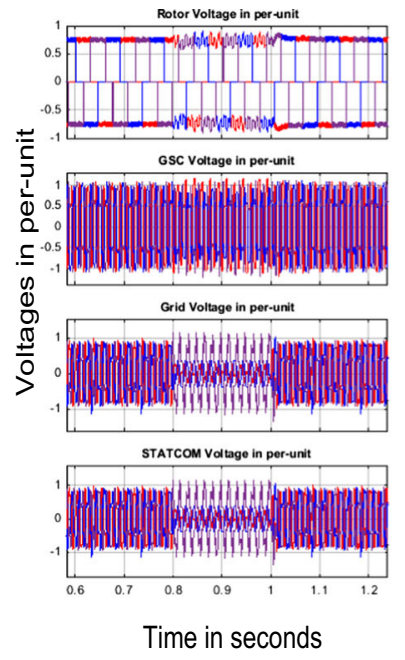

(b)



(c)

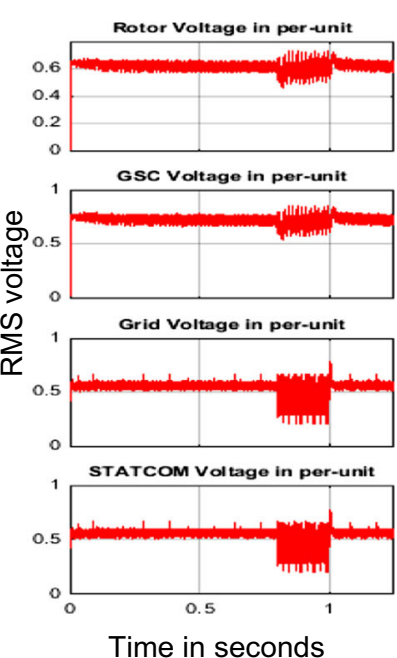

(d)

Fig. 11 Rotor, Stator, Grid and STATCOM instantaneous voltage a without STATCOM and b with STATCOM for DLG fault and rms voltage c without STATCOM and d with STATCOM 




(a)

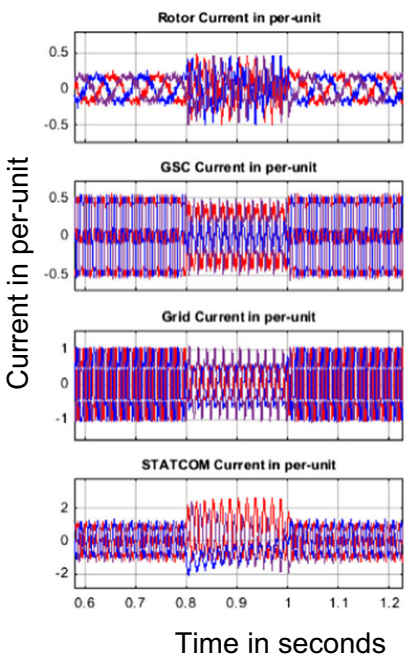

(b)

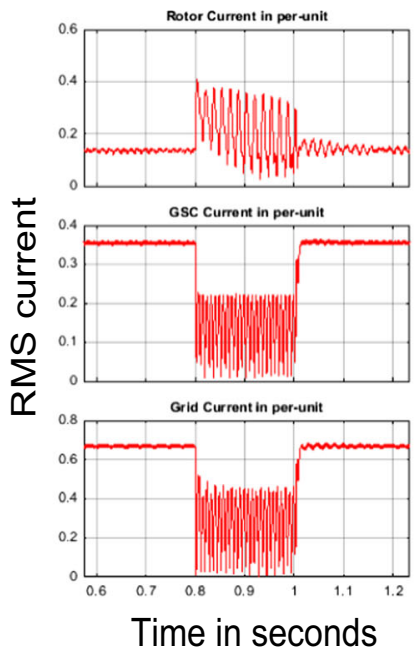

(c)



Gsc Current in per-unit



STATCOM Current in per-unit

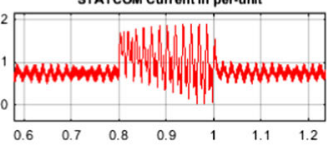

Time in seconds

(d)

Fig. 12 Rotor, Stator, Grid and STATCOM instantaneous current a without STATCOM and b with STATCOM for DLG fault and rms voltage $\mathbf{c}$ without STATCOM and $\mathbf{d}$ with STATCOM

results when compared with [21] or [22], proposed control strategy is having less dip in machine parameters voltage. The tansient voltage and current are controlled effectively if STATCOM was incoroparated. However with STATCOM, current in fault line also be improved to its pre-fault state. It is to be noted that ISFOC technique cant improve grid voltage or current and is done soley by STATCOM.

\section{Case b: Three Line to Ground (TLG) Fault Without and with} STATCOM A very severe symmetrical fault called TPG occurs at PCC during 0.8 to $1 \mathrm{~s}$ with same fault resistance of $0.001 \Omega$. The rotor, stator, grid and STATCOM voltage waveforms without and with STATCOM are shown in Fig. $14 \mathrm{a}$ and $\mathrm{b}$. The rotor voltage decreases from $0.9 \mathrm{pu}$ reference to $0.45 \mathrm{pu}$ during fault and increased from 0.45 pu to 2.2 pu immediately after fault clearance without
STATCOM. Without ISFOC, the rotor voltage further decreased to $0.2 \mathrm{pu}$ and increased beyond $3.1 \mathrm{pu}$ which is not shown here can be observed in references [21, 22]. With ISFOC and STATCOM controller, the drop in rotor voltage was minimized from 0.9 pu to 0.85 pu during fault and impulse rise immediately after fault is $1.04 \mathrm{pu}$.

The rotor, stator, grid and STATCOM instantaneous current waveforms without and with STATCOM are shown in Fig. 15a and b and rms current and voltage waveforms are shown in Fig. 15c and d. Since for a system without STATCOM, the STATCOM voltage and current will be zero. So, they are not shown in the waveforms. During the fault, fault current increases from $0.2 \mathrm{pu}$ to $0.49 \mathrm{pu}$ and decreased slowly during fault and post fault disturbances are also high without STATCOM. The rotor frequency during and just after fault change from slip frequency to higher



(a)



(b)

Fig. 13 DC capacitor voltage of DFIG converters and rotor speed $\mathbf{a}$ without STATCOM and $\mathbf{b}$ with STATCOM for DLG fault 


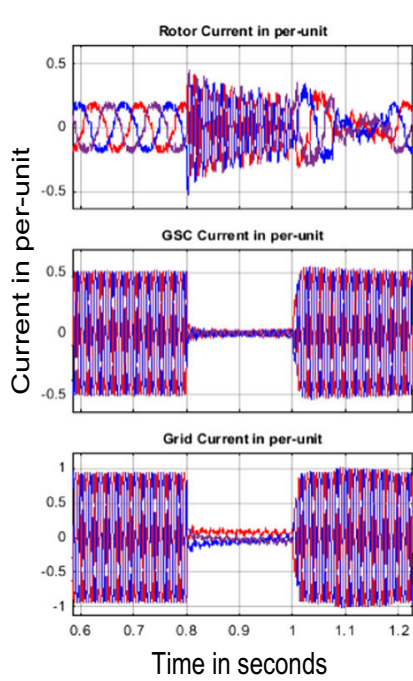

(a)

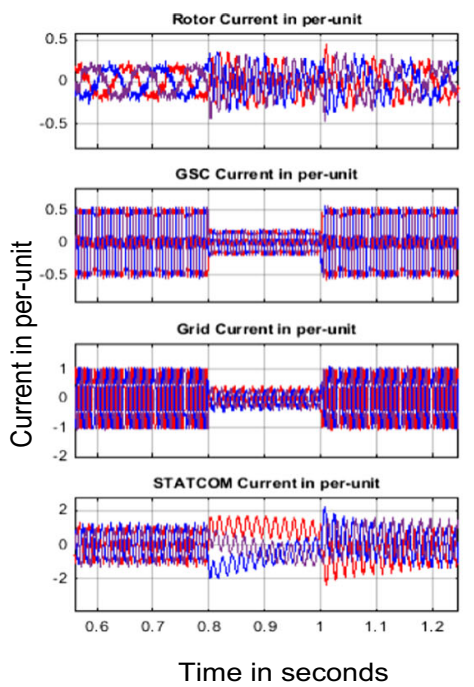

(b)



(c)

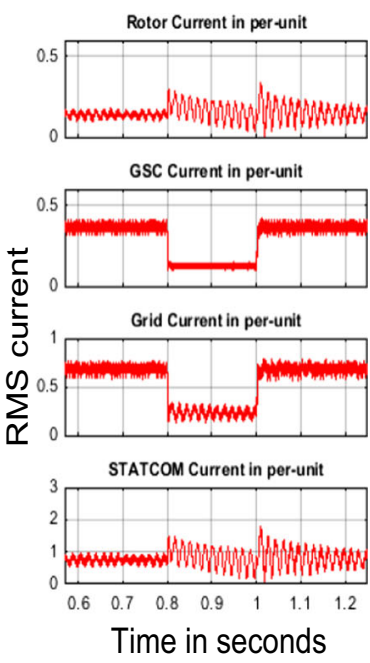

(d)

Fig. 14 Rotor, Stator, Grid and STATCOM instantaneous current a without STATCOM and b with STATCOM for TLG fault and rms voltage $\mathbf{c}$ without STATCOM and $\mathbf{d}$ with STATCOM

value and reaches its normal state. With STATCOM, rotor current changes from 0.2 pu to 0.38 pu small change in rotor frequency and harmonics in rotor current waveform. STATCOM improves performance by minimizing rotor current oscillations. The instant current during the fault without STATCOM at rotor side is changed from $1.8 \mathrm{pu}$ to $0.35 \mathrm{pu}$ and slowly regaining to its normal value during the fault. But once fault is cleared, this current again increased and decreased due to change in the flux values. This fluctuation in current is observed to be reduced when STATCOM is used. Similarly, the current fluctuation for GSC and grid are also observed to be reduced with STATCOM controller. The rms voltage on the rotor side decreased from 0.6 pu to 0.4 pu during the fault and once the fault is cleared as in Fig. 16c and d, this voltage increased to a very greater value without STATCOM. However, the voltage across the rotor during the fault is nearly constant and is observed that there is no surge voltage produced when the fault is cleared. Similarly, the performance of STATCOM and DFIG with proposed technique is clearly visible from the GSC and grid side voltage waveforms.

The drop in stator surge instant voltage during and just after fault without and with STATCOM, the fault voltage decreased from 1 pu to 0.48 pu and 3.75 pu during fault and immediate fault relieving operation without STATCOM. The voltage value of stator was improved by STATCOM and



(a)

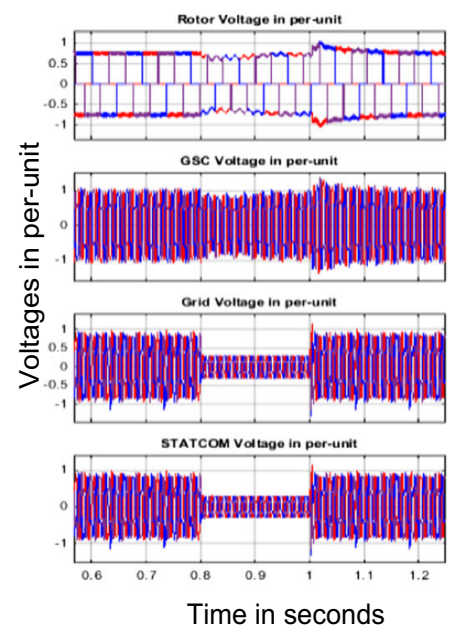

(b)

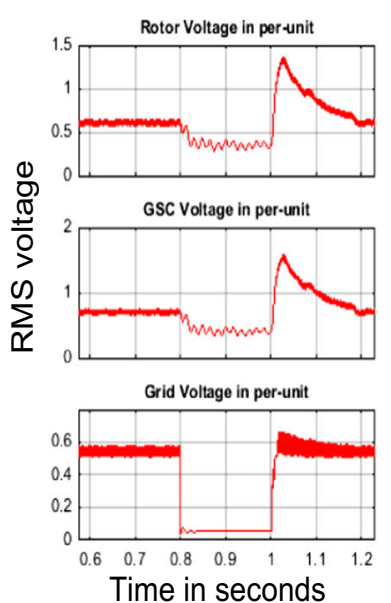

(c)

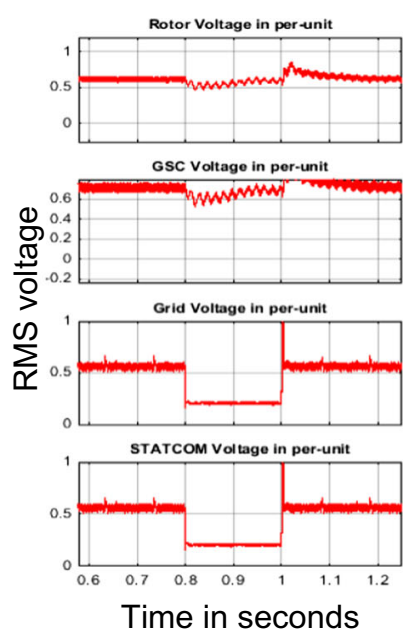

(d)

Fig. 15 Rotor, GSC, Grid and STATCOM instantaneous voltage a without STATCOM and b with STATCOM for TLG fault and rms voltage c without STATCOM and d with STATCOM 


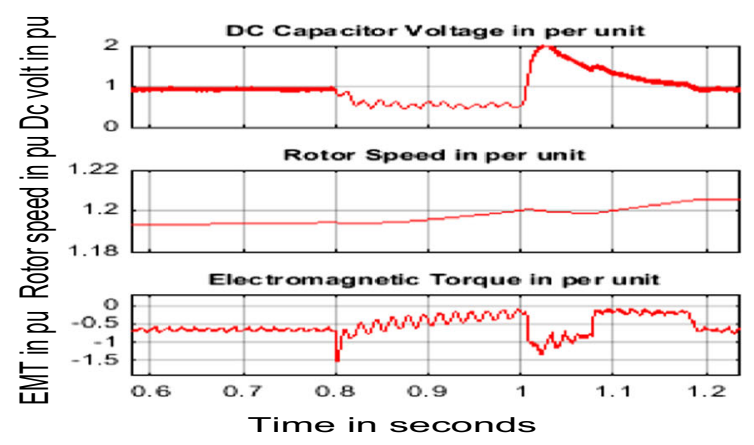

(a)

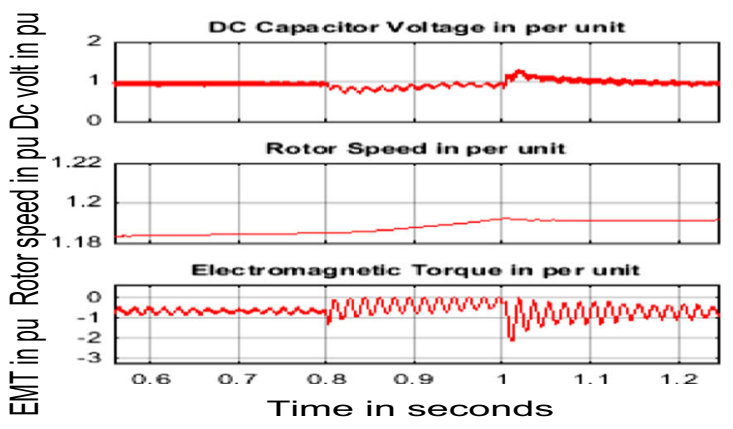

(b)

Fig. 16 DC capacitor voltage of DFIG converters and rotor speed $\mathbf{a}$ without STATCOM and $\mathbf{b}$ with STATCOM for TLG fault

helps in maintaing its during and post fault voltage value nearly constant. Also it is observed that during such severe fault, stator current decreased to very small value and is improved with STATCOM. With the help of ISFOC, during this type of very severe fault with very low impedance value, stator current reaches its pre-fault immediately rather than slowly increasing. It was observed that with falut resistance value greater than $0.06 \Omega$, compensation of stator current is $100 \%$ than without using ISFOC. The grid voltage and current values without STATCOM was improved with STATCOM, with decrease in both voltage and current values lesser in later case.

The DC voltage across capacitor is shown in Fig. 16a and $\mathrm{b}$ without and with STATCOM. It is observed that DC capacitor voltage decreases from nearly $480 \mathrm{~V}$ to $260 \mathrm{~V}$ during fault and increases drastically to $1400 \mathrm{~V}$ immediately after fault. Good GSC control scheme helps in maintaining DC voltage to certain value rather than becoming zero by absorbing fault current on grid side to reach to GSC and to charge capacitor. The rotor speed also maintained nearly constant with ISFOC, otherwise this value reaches beyond $1.4 \mathrm{pu}$ speed of rotor and makes it to rotate at dangerous speed which may damage rotor windings of DFIG. But with STATCOM, decrease in DFIG back-to-back capacitor is low and also post fault DC current was only changed from $480 \mathrm{~V}$ to $600 \mathrm{~V}$ and reaches its $480 \mathrm{~V}$ value in very small time period. Hence overall system behaviour was improved. From the STATCOM voltage and current waveforms, it is observed that STATCOM voltage decreased and current level was increased so as to improve the injection current and load angle of it. During steady state operation, the STATCOM current was around 25 Amps and during fault it reaches to nearly $100 \mathrm{amps}$ to compensate stator and rotor current and voltage and thereby grid terminal voltage and current values for enhanced stability and performance.

The DFIG WECS system is said to be in better operation when it provides good quality of power even when there are disturbances due to fluctuating wind speeds or grid faults. A good LOW VOLTAGE RIDE THROUGH system will be ensued by improving dynamic stability by obeying respective country's wind grid codes. The proposed system offers LOW VOLTAGE RIDE THROUGH capability as per NORDIAC grid code. The transient over current minimized in rotor circuit was advanced using ISFOC technique and STATCOM controller avoiding crowbar application which has drawback of throwing grid into more vulnerable condition by challenging reactive power.

The dynamic behaviour of overall system was improved by limiting fault and post fault transient currents entering in generator system by making lethargic system to reach its steady value at an improved rate. Hence good quality and reliable power with the aid of ISFOC and STATCOM will be achievable.

\section{Conclusion}

The proposed technique shows the effectiveness of ISFOC technique and STATCOM controller and a comparison was made with and without STATCOM in all aspects of rotor, stator, grid and STATCOM voltages, current, dc capacitor voltage and rotor speed during and after three phase symmetrical and asymmetrical faults. The effect of DLG fault with ISFOC does not cause much disturbance without or with STATCOM than in comparison with conventional FOC technique. Here both voltage of both stator and rotor remained constant while current there is some change in current in these. However grid voltage and current got disturbed due to the same fault proves the efficacy of ISFOC technique. There are certain ripples in DC voltage at capacitor at back-to-back points of DFIG converters and not getting drooped to lower voltage value in comparing with general FOC. With STATCOM, ripples in DC voltage got much lesser. Rotor speed is nearly constant during and after transient recovery operation.

Impact of transmission line/ grid disturbances such as under voltage grid faults for DFIG is studied. A new control scheme has to be developed to further reduce the impact 
of these faults on DFIG system is carried out. Since, the converter ratings of DFIG is only $30 \%$, injection of reactive power, dc voltage control across the converters will be little low even with a sophisticated control scheme. Hence, external real and/ or reactive power sources like STATCOM based FACTS device is used to improve the impact on system performance during abnormal grid conditions is analyzed.

\section{Appendix}

The parameters of each DFIG used in simulation are, Rated Voltage $=690 \mathrm{~V}$, Rated Power $=10 * 0.73 \mathrm{MW}$, base power $=$ $7 \mathrm{MW}$, Stator Resistance Rs $=0.0049 \mathrm{pu}$, Stator Leakage Inductance $\mathrm{Lls}=0.093 \mathrm{pu}$, Inertia constant $=4.54 \mathrm{pu}$, Mutual Inductance $\mathrm{Lm}=3.39 \mathrm{pu}$, rotor Resistance $\mathrm{Rr}=$ $0.0049 \mathrm{pu}$, Rotor Leakage inductance Llr1 $=0.1 \mathrm{pu}, \mathrm{DC}$ link Voltage $=415 \mathrm{~V}$, DC link capacitance $=0.002 \mathrm{~F}$, nominal wind speed $=12 \mathrm{~m} / \mathrm{s}$, Number of poles $=4$, Grid frequency $=60 \mathrm{~Hz}$, Grid Voltage $=25 \mathrm{KV}$, Rotor side filter: $\mathrm{Rfr}=0.3 \mathrm{~m} \Omega, \mathrm{Lfr}=0.6 \mathrm{nH}$, Grid side Filter: $\mathrm{Rfg}=0.3 \Omega$, $\mathrm{Lfg}=0.6 \mathrm{nH}$.

\section{References}

1. Ananth DVN, Kumar GVN, Gayathri T (2013) Analysis and design of enhanced real and reactive power control schemes for grid connected doubly fed induction generator. In: Proceedings of the IEEE INDICON, pp 1-6

2. Gayathri T, Ananth DVN, Kumar GVN, Sivanagaraju G (2013) Enhancement in dynamic and low voltage ride through behaviour of an ISFOC controlled DFIG with integrated battery energy storage system. In: Proceedings of the IEEE INDICON, pp 1-6

3. Asha Rani MA (2014) An effective reference generation scheme for DFIG with unbalanced grid voltage. IEEE Trans Sustain Energy 5(3):1010-1018

4. Mokryani G, Siano P, Piccolo A, Chen Z (2013) Improving fault ride-through capability of variable speed wind turbines in distribution networks. IEEE Syst J 7(4):713-722

5. Liang J, Qiao W, Harley RG (2010) Feed-forward transient current control for low-voltage ride-through enhancement of DFIG wind turbines. IEEE Trans Energy Convers 25(3):836-843

6. Ma L, Zheng Y, Ma H (2011) Research and simulation of doublefed wind power generation rotor side control technology. In: 2011 international conference electrical and control engineering (ICECE), pp 2472-2475

7. Sylvain LS (2010) Voltage oriented control of three-phase boost PWM converters. M.S. Thesis, Dept. Elec. Power Eng., Chalmers Univ. of Tech., Goteborg, Sweden

8. Pokharel B (2011) Modeling, control and analysis of a doubly fed induction generator based wind turbine system with voltage regulation. M.S. Thesis, Dept. Elec. Eng., Tennessee Tech. Univ., Cookeville, Tennessee

9. Abdou AF, Abu-Siada A, Pota HR (2012) Application of STATCOM to improve the LVRT of DFIG during RSC firethrough fault. In: Proceedings of IEEE AUPEC, 2012 22nd Australasian, pp 1-6

10. Beheshtaein S (2014) Optimal hysteresis based DPC strategy for STATCOM to augment LVRT capability of a DFIG using a new dynamic references method. In: Proceedings of IEEE ISIE, pp 612-619

11. Shi J, Furness I, Kalam A, Shi P (2013) On low voltage ridethrough and stability of wind energy conversion systems with FACTS devices. In: Proceedings of IEEE AUPEC, pp 1-6

12. Mohaghegh Montazeri M, Xu D, Yuwen B (2011) Improved low voltage ride thorough capability of wind farm using STATCOM. In: Proceedings of IEEE IEMDC, pp 813-818

13. Lopez J, Sanchis P, Roboam X, Marroyo L (2007) Dynamic behavior of the doubly fed induction generator during three-phase voltage dips. IEEE Trans Energy Convers 22:709-717

14. Okedu KE, Muyeen SM, Takahashi R, Tamura J (2011) Comparative study of wind farm stabilization using variable speed generator and FACTS device. In: 2011 IEEE GCC conference and exhibition (GCC), pp 569-572

15. Morren J, de Haan SWH (2005) Ride through of wind turbines with doubly-fed induction generator during a voltage dip. IEEE Trans Energy Convers 20:435-441

16. Seman S, Niiranen J, Arkkio A (2006) Ride-through analysis of doubly fed induction wind-power generator under unsymmetrical network disturbance. IEEE Trans Power Syst 21:1782-1789

17. Erlich I, Wrede H, Feltes C (2007) Dynamic behavior of DFIGbased wind turbines during grid faults. In: Power conversion conference - Nagoya, 2007. PCC '07, pp 1195-1200

18. Pannell G, Zahawi B, Atkinson DJ, Missailidis P (2013) Evaluation of the performance of a DC-link brake chopper as a DFIG low-voltage fault-ride-through device. IEEE Trans Energy Convers 28(3):535-542

19. Pal BC, Coonick AH, Macdonald DC (2000) Robust damping controller design in power systems with superconducting magnetic energy storage devices. IEEE Trans Power Syst 15:320-325

20. Serhiy V, Bozhko RB-G, Li R, Clare JC, Asher GM (2007) Control of offshore DFIG-based wind farm grid with line-commutated HVDC connection. IEEE Trans Energy Convers 22(1): 71-78

21. Bozhko S, Asher G, Li R, Clare J, Yao L (2008) Large offshore DFIG-based wind farm with line-commutated HVDC connection to the main grid: engineering studies. IEEE Trans Energy Convers 23(1):119-127

22. Qiao W, Harley RG, Venayagamoorthy GK (2009) Coordinated reactive power control of a large wind farm and a STATCOM using heuristic. IEEE Trans Energy Convers 24(2):493-503

23. Qiao W, Venayagamoorthy GK, Harley RG (2009) Real-time implementation of a STATCOM on a wind farm equipped with doubly fed induction generators. IEEE Trans Ind Appl 45(1):98107

24. Wang L, Hsiung C-T (2011) Dynamic stability improvement of an integrated grid-connected offshore wind farm and marine-current farm using a STATCOM. IEEE Trans Power Syst 26(2):690-698

25. Mahmoud MS, Xia Y (2013) Analysis and synthesis of faulttolerant control systems. Wiley, New York 